\title{
Determination of Moisture in Powder and Lyophilised Saffron (Crocus sativus L.) by Karl Fischer Method
}

\author{
Daniele Naviglio ${ }^{1}$, Stefano Conti $^{2}$, Lydia Ferrara ${ }^{3}$ and Antonello Santini*, ${ }^{*}$ \\ ${ }^{I}$ Department of Food Science, University of Naples "Federico II", Via Università, 100 - 80055 Portici (Napoli), Italy \\ ${ }^{2}$ Department of Arboriculture Botany and Plant Pathology, University of Naples "Federico II", Via Università, 100 - \\ 80055 Portici (Napoli), Italy \\ ${ }^{3}$ Department of Pharmaceutical Chemistry and Toxicology, University of Naples "Federico II", Via Montesano, 49 - \\ 80131 Napoli, Italy
}

\begin{abstract}
Saffron is a spice obtained from the dried stigmas of the purple-flowered saffron crocus (Crocus sativus L.). The determination of the water content in saffron is very important in order to establish its microbiological stability and consequently to determine the commercial value. The average moisture content in dried saffron powder ranges between $10-12 \%$ causing a slow degradation of the product. On the other hand lyophilised saffron has lower water content and a better stability. The reference method commonly used for the determination of moisture in saffron it is based on the gravimetric loss of weight after heating at $105^{\circ} \mathrm{C}$ for 16 hours.

In this paper a procedure to obtain lyophilised saffron is proposed and two different methods, namely the infrared balance and the Karl Fischer titration, are used to determine moisture in dried and lyophilised saffron powder, and results are compared with the reference method. The Karl Fischer method, never applied so far to determine moisture in saffron, gave the best results. The average values determined were $6.87 \%$ and $4.01 \%(\mathrm{w} / \mathrm{w})$ for conventionally dried and lyophilised saffron powder, respectively. The Karl Fischer titration method allows to determine in a faster manner the moisture in saffron powder and in lyophilised saffron, without any interference and using a minor quantity of saffron compared to the gravimetric procedure reported in the reference method. The volatile matter content, differently from the reference method, this way is not determined.
\end{abstract}

Keywords: Water, moisture, Karl Fischer, lyophilised saffron, saffron powder, crocins.

\section{INTRODUCTION}

Saffron is a spice obtained from the dried yellowish orange $2.5-4 \mathrm{~cm}$ long stigmas of the purple-flowered saffron crocus (Crocus sativus L.) of the iris family, Iridaceae, native to Southern Europe and the Middle East, and it is so named from Arabic term "zaferan", meaning yellow. Saffron has an aromatic hot and slightly bitter taste and contains different water-soluble colouring substances, the crocins, which provide a golden-coloured dye effective even at a dilution of 1:100.000 (w/v). This spice has been used since ancient times as a food additive and as dye, and it has been also used as a drug to treat various human health conditions [1]. Recently, its properties as antidepressant [2] and as antitumoral against different malignant cells have been demonstrated [3, 4]. Saffron is among the most valuable, most expensive spices in the world, since harvesting saffron is very labourintensive, considering the low number of flowers per hectar and the work required for harvesting it [5]. Each blossom has three stigmas, which are picked by hand in the morning before the heat of the day, and then dried by heating or sun dried for 15-30 minutes, while the blossoms are thrown away. Saffron is also very hygroscopic, the exposure to

*Address correspondence to this author at the Department of Food Science, University of Naples "Federico II", Via Università, 100 - 80055 Portici (Napoli), Italy; Tel/Fax: 003981 2539317; E-mail: asantini@unina.it moisture creating a risk of spoilage of the product. It has been determined for a typical saffron sample, before drying, that the relative humidity is about $70 \%$, while the essential oil content in particular of the picrocrocin (saffron-bitter) is between $0.4-1.3 \%(\mathrm{w} / \mathrm{w})$, and the water content is $9-10 \%$ (dried final product) and $12-18 \%$ (wooden packaging) [6]. The postharvest treatment of drying stigmas is necessary to reduce the moisture to a value below $15 \%$ and to obtain a product microbiologically stable in time. To the date, drying is carried out at temperatures comprised between $20^{\circ} \mathrm{C}$ and $120{ }^{\circ} \mathrm{C}$, depending on the local tradition and on the procedure used, usually until the colour of the stigmas changes from orange-red to dark red, as an evidence of the end of the drying. The practice of sun drying stigmas (prevalent in India) was perceived likely as a major cause of poor quality and alternative methods were studied in order to determine their effectiveness and commercial practicability $[7,8]$. In sun drying, stigmas are dried for 3-5 days in the sun till the moisture content is reduced to $10-12 \%$. Alternatively, during flowers harvest, the whole flowers are dried in the sun and stigmas are picked by hand from the dried flowers later [9]. The dried, warm saffron is then allowed to cool in a dry place [10]. Exposing the fresh stigmata of saffron to a hot source for many hours can cause reactions to happen between the native components of saffron like crocins and water, part of which evaporates. 
The crocins are the glycosyl esters of crocetin $\left(\mathrm{C}_{44} \mathrm{H}_{64} \mathrm{O}_{24}\right)$ that are unusually water-soluble carotenoids responsible for the strong colouring capacity of saffron. Picrocrocin $\left(\mathrm{C}_{16} \mathrm{H}_{26} \mathrm{O}_{7}\right)$ a monoterpene glycoside and safranal $\left(\mathrm{C}_{10} \mathrm{H}_{14} \mathrm{O}\right)$ are the principal bitter tasting substances in saffron. Safranal, a monoterpene aldehyde, is formed in saffron by hydrolysis during drying and storage from picrocrocin and is responsible for its aroma [11]. The water content in the dried product directly influences the amount of these valuable compounds contained in the spice.

Recently, different papers about the optimum drying conditions to obtain the best hot dried spice [12] and about dehydration postharvesting treatment to reduce moisture in stigmas were published [7,8].

In the literature different aspects of saffron, principally referring to the analysis and identification of main components have been evaluated, as well as the identification of bioactive molecules contained in saffron like crocins for their possible use in medicine [3] while no method has been proposed for the determination of water content in dried saffron powder except for the "determination of moisture and volatile matter" indicated at point 9 of International Standard Regulation ISO 3632-2-93, based on the gravimetric measure of the loss of weight in oven at $103{ }^{\circ} \mathrm{C} \pm 2{ }^{\circ} \mathrm{C}$. According to the ISO, the determination gives the total of water and volatile matter present, without the possibility to separate the two amounts [13].

In this paper the Karl Fischer (KF) titration method [14] is proposed to determine the water content in saffron powder and in lyophilised saffron. The use of lyophilization procedure here described is new for saffron; it uses low temperatures in a high vacuum environment to dry the spice reducing the risk of reactions between the native substances contained in the spice and allowing to obtain saffron with a constant content of the native compounds. The results obtained with the KF and gravimetric infrared balance methods are compared to those obtained with the official ISO method.

\section{MATERIALS AND METHODOLOGY}

\section{Materials}

Saffron was obtained from two Italian producers, namely Sanna, S. Gavino Monreale (Cagliari) and Navelli, Civitaretenga (L'Aquila), and one from an Iranian producer, Bahraman Saffron (Masshad). All saffron powder samples were classified according to the ISO classification as Category I (see Table 1). Lyophilised saffron was prepared as described below.
For each of the four saffron typology under study (Sanna, Navelly, Bahraman, lyophilised) five aliquots were sampled and analysed using the ISO, the infrared balance and KF method, respectively, to determine the water content. Each sample was analysed in triplicate and results were reported as the average. Considering that for the saffron powder the analytical identification and hence the commercial classification according to the ISO 3632-2-93 [13] is based on the spectrophotometric determination of crocins, picrocrocins and safranal since their amount in the dried product is dependent on the moisture content. Crocins, picrocrocins and safranal have been identified and quantified using UV spectroscopy determination of the absorbance maxima at 257 , 330 and $440 \mathrm{~nm}$, for picocrocins, safranal and crocins, respectively.

\section{Lyophilised Saffron Preparation}

Lyophilised saffron was obtained from the sample furnished by the producer Sanna as following: $250 \mathrm{~g}$ of fresh stigmas of Crocus sativus L. were, immediately after collecting in field, frozen at $-20{ }^{\circ} \mathrm{C}$ for twenty four hours; then they were lyophilised for other 24 hours, powdered by grinding to obtain $50 \mathrm{~g}$ of orange coloured powered saffron. Fig. (1) shows the aspect of the starting material used.

\section{Determination of Moisture by Standard Gravimetric Method}

$2.5 \mathrm{~g}$ of saffron stigmas previously powdered by grinding, were dried in an oven (Intercontinental s.r.l.) at $103{ }^{\circ} \mathrm{C} \pm$ $2^{\circ} \mathrm{C}$ for 16 hours at atmospheric pressure; after cooling in the dryer, the sample was weighted to the nearest $0.0001 \mathrm{~g}$. A test for constancy of mass was performed by additional drying steps of $1 \mathrm{~h}$ until the difference in the mass did not exceed $0.5 \mathrm{mg}$. Each sample was analyzed in triplicate and the final result reported as the average on all the determinations (ISO 3632-2-93).

\section{Determination of Moisture Using the Infrared Balance}

$5.0 \mathrm{~g}$ of each sample of saffron powder were dried on an infrared balance (Eurotherm, Gibertini, Novate, Italy) at 105 ${ }^{\circ} \mathrm{C}$ until the weight was constant (the difference between two consecutive determination did not exceed $4.0 \mathrm{mg}$ ) for $5 \mathrm{~min}$ utes. Each measure required about 20 minutes. Each sample was analyzed in triplicate and the final result taken as the arithmetic average on all the determinations.

\section{Determination of Moisture by Volumetric Karl-Fischer Titration}

The determinations of moisture were carried out using a micro ST 2038 apparatus for Karl Fischer titration (Crison

Table 1. Commercial Classification of Saffron According to the ISO 3632-2-93; $\mathrm{E}_{\lambda}^{1 \%}$ is the Specific Extinction Coefficient

\begin{tabular}{|c|c|c|c|}
\hline Category & "Bitterness" $\mathbf{E}^{1 \%}{ }_{257}$ & “Odour" $\mathbf{E}^{1 \%}{ }_{330}$ & “Colour" $E^{1 \%}{ }_{440}$ \\
\hline I & $\geq 70$ & $20-50$ & $\geq 190$ \\
\hline II & $\geq 55$ & $20-50$ & $\geq 150$ \\
\hline III & $\geq 40$ & $20-50$ & $\geq 110$ \\
\hline IV & $\geq 30$ & $20-50$ & $\geq 80$ \\
\hline Powder saffron (this paper) & 100 & 35 & 240 \\
\hline Lyophilised saffron (this paper) & 230 & 100 & 330 \\
\hline
\end{tabular}




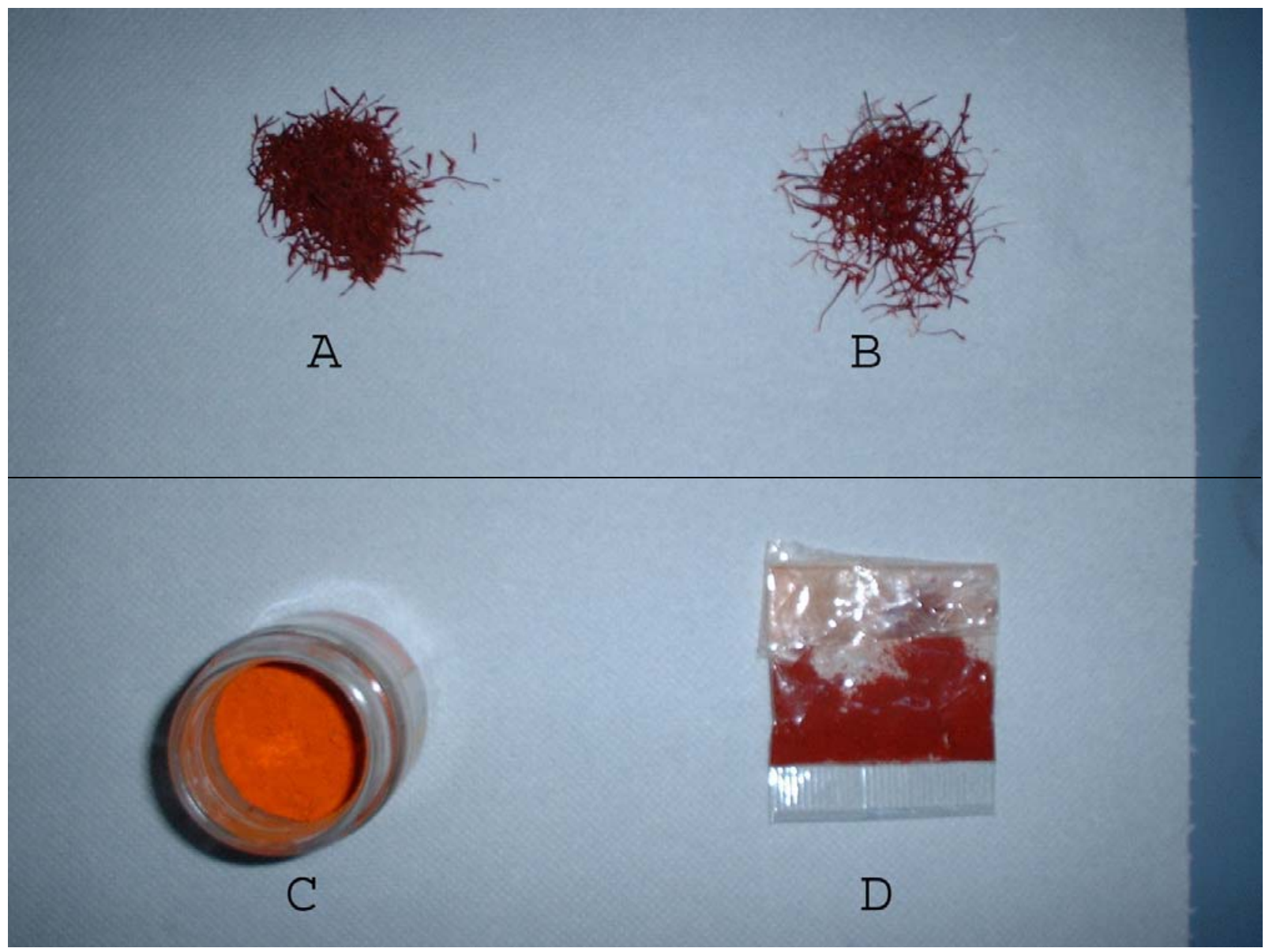

Fig. (1). Samples of iranian saffron (A), Sanna italian saffron (B), lyophilized saffron (C), and Navelli powder saffron (D).

Instruments SA, Spain). $70.0 \mathrm{mg}$ of saffron lyophilised and $20.0 \mathrm{mg}$ of powder saffron were analysed with Hydranal composite 5 (Hydranal solvent, Fluka) as reagent and methanol as solvent. The solvent was changed in each experiment. The analyses were performed in triplicate and the results averaged.

\section{UV-VIS Spectrophotometric Analysis}

Samples of saffron powder and lyophilised saffron were dissolved in water at a $0.04 \%$ and $0.02 \%(\mathrm{w} / \mathrm{v})$, respectively and filtered through $0.20 \mu \mathrm{m}$ membrane (Millipore, Bedford, MA, USA) in order to eliminate rough impurities. They were then analysed using a spectrophotometer UV-VIS mod. UV1601 (Shimadzu Corp., Tokyo, Japan) in the $200-600 \mathrm{~nm}$ wavelength range.

\section{RESULTS AND DISCUSSION}

Absorbance values limits used for the commercial classification of the powder saffron in the four existing categories [13] are reported in Table $\mathbf{1}$ for reference together with the values determined for the samples analysed in this study.

Table 2 shows the results obtained using the three methods above described for the water content determination using powder and lyophilised saffron.

Standard deviation is good for all of the three methods, but the values of moisture determined by oven drying (ISO method) are always higher than the others. This reflects the loss of weight caused by the chosen conditions and do not necessarily reflect the true water content: in fact the weight loss could be caused not only by the water, but also by the loss of volatile substances present in the powder or formed by degradation reactions related to the sample heating. The process of drying using the infrared balance is based on the irradiation of the sample with infrared radiation that is capable to induce the evaporation of the water contained in the sample. About $5 \mathrm{~g}$ of sample are required and the measure is relatively fast, about 20 minutes, while for the standard ISO method about $2.5 \mathrm{~g}$ and 16 hours are required.

In the literature many papers describe the use of the Karl Fischer titration method in the determination of the water content in foodstuffs. Recently its use in the determination of the water content in powdered milk was proposed $[15,16]$.

The Karl-Fischer titration [14, 17, 18] on the other hand is the only selective method even if, due to the nature of the titration, it is impossible to measure the moisture in a sample if the water content is too high. This method in fact is capable to determine very low moisture content in the sample and has the smallest standard deviation when applied to saffron (see Table 2). The quantity needed for the determination is very small, $70 \mathrm{mg}$ and $20 \mathrm{mg}$ for the dried and lyophilised saffron powder, respectively, and the determination is very fast, requiring about 1 minute. 
Table 2. Weight Loss Percentage (w/w \%) in: (A) Lyophilized Saffron, (B) Powder Saffron Sanna, (C) Powder Saffron Navelli, and (D) Powder Saffron Iran, Determined by ISO Method, Infrared Balance and KF Titration. For the KF Method the Reported Values Coincide with the Water Content

(A)

\begin{tabular}{|c|c|c|c|}
\hline Lyophilized Saffron & Oven Drying (w/w \%) & Infrared Balance (w/w \%) & KF Titration (w/w \%) \\
\hline \hline 1 & 10.00 & 6.88 & 3.83 \\
\hline 2 & 9.64 & 6.41 & 4.34 \\
\hline 3 & 9.15 & 7.01 & 4.10 \\
\hline 4 & 10.10 & 7.20 & 3.95 \\
\hline 5 & 9.87 & 6.69 & 4.05 \\
\hline average & 9.75 & 6.84 & 4.05 \\
\hline SD & 0.31 & 0.25 & 0.16 \\
\hline
\end{tabular}

(B)

\begin{tabular}{|c|c|c|c|}
\hline Powder Saffron (Sanna) & Oven Drying (w/w \%) & Infrared Balance (w/w \%) & KF Titration (w/w \%) \\
\hline \hline 1 & 11.0 & 7.88 & 6.92 \\
\hline 2 & 10.64 & 7.41 & 6.75 \\
\hline 3 & 9.99 & 8.99 & 6.03 \\
\hline 4 & 10.1 & 8.2 & 6.82 \\
\hline 5 & 12.87 & 7.0 & 6.83 \\
\hline average & 10.92 & 7.90 & 6.87 \\
\hline SD & 0.95 & 0.62 & 0.09 \\
\hline
\end{tabular}

(C)

\begin{tabular}{|c|c|c|c|}
\hline Powder Saffron (Navelli) & Oven Drying (w/w \%) & Infrared Balance (w/w \%) & KF Titration (w/w \%) \\
\hline \hline 1 & 11.22 & 7.76 & 6.63 \\
\hline 2 & 10.04 & 7.81 & 6.55 \\
\hline 3 & 9.89 & 8.00 & 6.01 \\
\hline 4 & 10.33 & 8.23 & 6.64 \\
\hline 5 & 12.87 & 7.56 & 6.97 \\
\hline average & 10.87 & 7.87 & 6.76 \\
\hline SD & 1.01 & 0.21 & 0.17 \\
\hline
\end{tabular}

(D)

\begin{tabular}{|c|c|c|c|}
\hline Powder Saffron (Iran) & Oven Drying (w/w \%) & Infrared Balance (w/w \%) & KF Titration (w/w \%) \\
\hline \hline 1 & 11.22 & 7.36 & 6.83 \\
\hline 2 & 10.04 & 7.21 & 6.95 \\
\hline 3 & 9.08 & 8.04 & 7.10 \\
\hline 4 & 10.53 & 8.13 & 6.34 \\
\hline 5 & 12.97 & 7.16 & 7.05 \\
\hline average & 10.77 & 7.58 & 6.85 \\
\hline SD & 1.19 & 0.38 & 0.25 \\
\hline
\end{tabular}


The determination of the water content of a sample requires a two step chemical reaction scheme that uses the reaction between iodine and water in presence of sulphur dioxide. The chemical reactions are the following:

$$
\begin{aligned}
& \mathrm{CH}_{3} \mathrm{OH}+\mathrm{SO}_{2}+\mathrm{RN}=[\mathrm{RNH}] \mathrm{SO}_{3} \mathrm{CH}_{3} \\
& {[\mathrm{RNH}] \mathrm{SO}_{3} \mathrm{CH}_{3}+\mathrm{I}_{2}+\mathrm{H}_{2} \mathrm{O}+2 \mathrm{RN}=[\mathrm{RNH}] \mathrm{SO}_{3} \mathrm{CH}_{3}+} \\
& 2[\mathrm{RNH}] \mathrm{I}
\end{aligned}
$$

The parameter measured in the volumetric KF method is the amount of iodine reduced in the second reaction step where $[\mathrm{RNH}] \mathrm{SO}_{3} \mathrm{CH}_{3}$ act as catalyst. The data reported in the Table 2 indicate that lyophilised saffron (Sanna producer) has the lowest content of water, $4.01 \%$, while the saffron conventionally dried obtained from the same producer has a value of $6.87 \%$. Comparing the data reported in the Table 2 it can be observed that the official ISO method gives always an higher water content compared with the infrared balance and Karl Fischer titration method. For the KF method the values reported in Table 2 coincide with the water content, since any other substance present in the sample in very small amount should not interfere with the Iodine used in the titration.

To determine the content of glycosilated compounds present in the dried and lyophilised saffron, UV spectroscopy was used. The results show that lyophilised saffron water solution at $0.02 \%(\mathrm{w} / \mathrm{v})$ concentration has an higher values for the absorbance at 257, 330 and $440 \mathrm{~nm}$, see Fig. (2A), compared to the saffron powder at a $0.04 \%(\mathrm{w} / \mathrm{v})$ concentration, see Fig. (2B). The higher absorbance at $440 \mathrm{~nm}$ is related to the highest crocins content, responsible for saffron colour, while the absorbance at $257 \mathrm{~nm}$ is related to the picrocrocins content, responsible for the taste, and the absorbance measured at $330 \mathrm{~nm}$ is related to the safranal content, responsible for the odour [19]. The higher crocins content in lyophilised saffron is due to its lower moisture content, in fact the moisture can catalyse the degradation (hydrolysis) of crocin into crocetin, causing also the fading of the colour in the saffron powder, the colour being inversely related to moisture content [9]. Liophylised saffron showed a colouring power ("Colour" $\mathrm{E}^{1 \%}{ }_{440}$ ) of 330 according to the data reported in Fig. (2A) while powder saffron showed a value of 240. The value for the lyophilized saffron is way higher then the 190 considered acceptable for the Category I classification (see Table 1) indicating that this formulate can be classified in a new higher Category.

Moreover since the traditional drying method of the saffron is realized using high temperatures for a long time, the native compounds, e.g. the crocins, can be degraded, also explaining why the traditionally dried saffron has a lower content of these compounds compared with the lyophilised saffron powder, that has also a lower water content.

\section{CONCLUSION}

The obtained results using the official ISO, the infrared balance and the KF titration method to determine the water content in saffron powder and lyophilised saffron powder allowed us to conclude that the KF method could be an alternative technique to measure the water content in saffron with respect to the method suggested by the ISO 3632-2-93 [13] and ISO 5725-1 [20] regulations, based on the loss of weight after oven drying. The results obtained by KF titra-
(A)

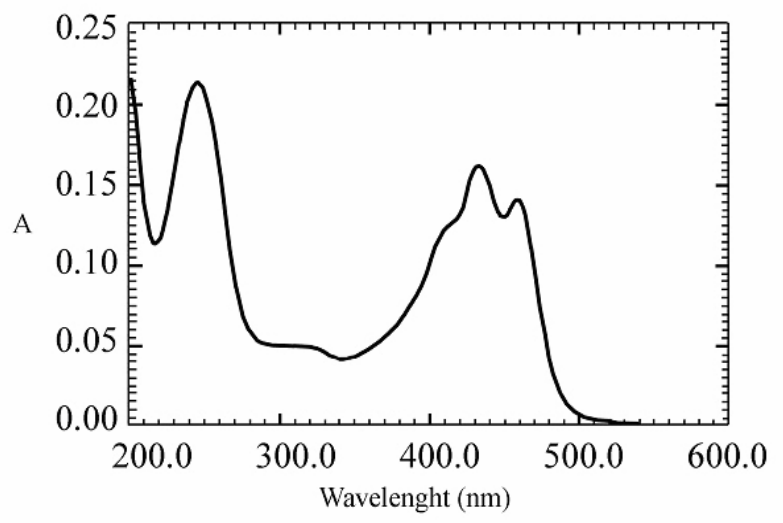

(B)

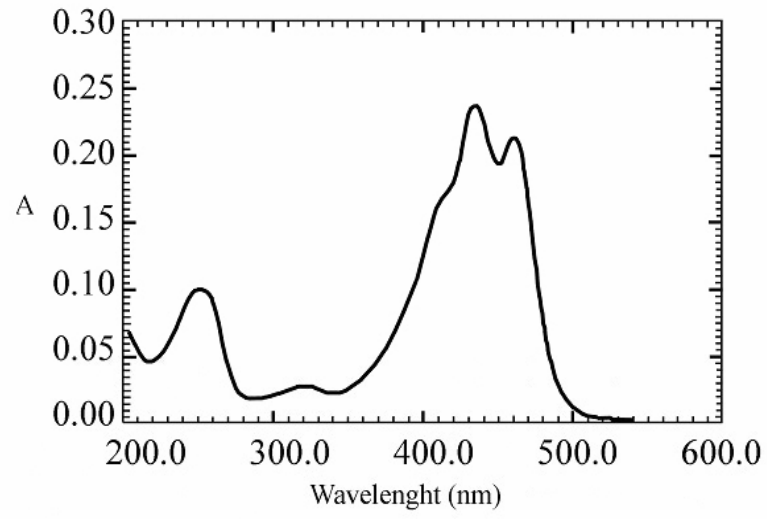

Fig. (2). UV-VIS (200-600 nm) spectra of lyophilised (A) and oven dried saffron (B); analysed solutions are at a 0.02 and $0.04 \%$ (w/v) concentration, respectively.

tion allowed us to obtain a good repeatability, good accuracy considering that any volatile compound is not determined, and a faster determination. Moreover a smaller quantity of sample for the analysis compared to the oven drying method is required.

Lyophilized saffron is a new product, with an higher content of crocins, a constant content of native compounds, because of its minimum water content (about 4\%) with respect to the traditional dried saffron and for this reasons it could be used as a standard substance to evaluate the quality and water content of saffron powder itself. At the same time we can conclude that the innovative method of lyophilisation here described, based on drying by freezing in a high vacuum, allows to obtain saffron with very low moisture content and consequently an higher crocins content, a longer shelf-life, a greater stability and an higher colouring power.

\section{REFERENCES}

[1] Hosseinzadeh H, Talebzadeh F. Anticonvulsant evaluation of safranal and crocin from Crocus sativus in mice. Fitoterapia 2005; 76: 722-4.

[2] Noorbala AA, Akhondzadeh S, Tahmacebi-Pour N, Jamshidi AH Hydro-alcoholic extract of Crocus sativus L. versus fluoxetine in 
the treatment of mild to moderate depression: a double-blind, randomized pilot trial. J Ethnopharmacol 2005; 97: 281-4.

[3] Escribano J, Alonso GL, Coca-Prados M, Fernandez JA. Crocin, safranal and picrocrocin from safron (Crocus sativus L.) inhibit the growth of human cancer cells in vitro. Cancer Lett 1996; 100: 2330 .

[4] Abdullaev FI. Cancer chemo preventive and tumoricidal properties of saffron (Crocus sativus L.). Exp Biol Med 2002; 227: 20-5.

[5] Basker D, Negbi M. Uses of saffron. Econ Bot 1983; 37: 228-36.

[6] Scharnow R. Codiertes Handbuch der Güter des Seetransports, VE Kombinat Seeverkehr und Hafenwirtschaft-Deutfracht/SeereedereiIngenieurhochschule für Seefahrt Warnemünde/Wustrow, Rostock Bd. 1: Stückgut A-K, Bd. 2: Stückgut L-Z, Bd. 3: Spezialgut, 1986.

[7] Carmona M, Zalacain A, Pardo JE, Lopez E, Alvarruiz A, Alonso GL. Influence of different drying and aging conditions on saffron constituents. J Agric Food Chem 2005; 53: 3974-9.

[8] Gregory MJ, Menary RC, Davies NW. Effect of drying temperature and air flow on the production and retention of secondary metabolites in saffron. J. Agric Food Chem 2005; 53: 5969-75.

[9] Raina BL, Agarwal SG, Bhatia AK, Gaur GS. Changes in pigments and volatiles of saffron (Crocus sativus L.) during processing and storage. J Sci Food Agric 1996; 71: 27-32.

[10] Ingram JG. Saffron (Crocus sativus L). Trop Sci 1969; 11: 177-86.

[11] Tarantilis PA, Polissiou M. Isolation and identification of the aroma components from saffron (Crocus sativus L.). J Agric Food Chem 1997; 45: 459-62.
[12] Selim K, Tsimidou M, Biliaderis CG. Kinetic studies of degradation of saffron carotenoids encapsulated in amorphous polymer matrices. Food Chem 2000; 71: 199-206.

[13] International Standard ISO 3632 1-2 Saffron (Crocus sativus L.), The International Organisation for Standardization, ${ }^{\text {st }}$ ed., Switzerland 1993.

[14] Bahari EP. Determination of small quantities of water by the Karl Fischer method. UK: Birmingham University Chemical Engineer 1956; vol. 7: pp. 70-9.

[15] Rückold S, Grobecker KH, Isengard HD. Determination of the contents of water and moisture in milk powder. Fresenius J Anal Chem 2000; 368: 522-7.

[16] Reh C, Bhat SN, Berrut S. Determination of water content in powdered milk. Food Chem 2004; 86: 457-64.

[17] Grünke S. Main and side reactions in the Karl Fisher solution. Food Control 2001; 12: 419-26.

[18] Grünke S. The influence of conductivity on the Karl Fisher titration. Food Chem 2003; 82: 99-105.

[19] Tarantilis PA, Tsoupras G, Polissiou M. Determination of saffron (Crocus sativus L.) components in crude plant extract using highperformance liquid chromatography-UV-visible photodiode-array detection-mass spectrometry. J Chromatogr A 1995; 699: 107-18.

[20] International Standard Part 1, ISO 5725-1 (1994), corrected 1998 (E), Part 2, ISO 5725-2:1994(E), Part 3, ISO 5725-3:1994(E), Part 4, ISO 5725-4:1994(E) International Organization for Standardization, Geneva, Switzerland, (1994/1998).

Received: August 29, 2009

(C) Naviglio et al.; Licensee Bentham Open.

This is an open access article licensed under the terms of the Creative Commons Attribution Non-Commercial License (http://creativecommons.org/licenses/by-nc/3.0/) which permits unrestricted, non-commercial use, distribution and reproduction in any medium, provided the work is properly cited. 